\title{
Bulky Aluminum Lewis Acids as Novel Efficient and Chemoselective Catalysts for the Allylation of Aldehydes
}

\author{
Andreas Marx, Hisashi Yamamoto* \\ Graduate School of Engineering, Nagoya University, CREST, Chikusa, Nagoya 464-8603, Japan \\ Fax +81(52)789-3222; E-mail: j45988@nucc.cc.nagoya-u.ae.jp
}

\begin{abstract}
Bulky aluminum Lewis acids such as MAD and MABR are introduced as new efficient catalysts in substoichiometric amounts for the allylation of aldehydes with allyltributylstannane. In addition, chemoselective allylation of a less hindered or aromatic aldehyde was achieved with catalytic amounts of the carbonyl receptor aluminum tris(2,6-diphenyl-phenoxide) (ATPH).
\end{abstract}

Keywords: allylation, allyltributylstannane, Lewis acid catalysis, MABR, ATPH

The Lewis acid promoted allylation of aldehydes using allystannanes or their less reactive counterparts allylsilanes is a versatile synthetic tool. ${ }^{1}$ Numerous Lewis acids like $\mathrm{TiCl}_{4}, \mathrm{SnCl}_{4}, \mathrm{BF}_{3} \cdot \mathrm{EtO}_{2}$, or $\mathrm{AlCl}_{3}$ promote this reaction but they seem to be required in stoichiometric amounts and there is little precedent for Lewis acid catalysis. Recently however, it has been shown that chiral (acyloxy)borane, ${ }^{2}$ silver(I), ${ }^{3}$ titanium(IV), ${ }^{4}$ zirconium (IV), ${ }^{5}$ and rhodium(III) ${ }^{6}$ complexes respectively, are capable of catalyzing the reaction of aldehydes with allystannanes or allylsilanes with excellent enantioselectivity, although reaction times are very long (up to 70 hours). Furthermore, these catalysts are often lacking broad substrate tolerance. Ytterbium trifluoromethanesulfonate has been recently introduced as catalyst for the allylation of aldehydes with allyltributylstannane. ${ }^{7}$ We would like to report here the hitherto unknown capacity of bulky organoaluminum reagents as very efficient catalysts for the reaction between aldehydes and allyltributylstannanes even when they are employed only in catalytic amounts.

To evaluate the ability of organoaluminum Lewis acids as suitable catalysts for allylation of aldehydes the reaction between benzaldehyde $\mathbf{1}$ and allyltributylstannane $\mathbf{2}$ was investigated as a test system. When $\mathrm{Me}_{3} \mathrm{Al}$ or $(i-\mathrm{PrO})_{3} \mathrm{Al}$, respectively, were used in substoichiometric amounts (10 mol\%) to catalyze this reaction only trace amounts of the desired homoallylic alcohol 3 were yielded even after prolonged reaction times and increased reaction temperatures (Table 1). However, 10 mol\% of $\left(p-\mathrm{MeC}_{6} \mathrm{H}_{4} \mathrm{O}\right)_{3} \mathrm{Al}$ was able to afford the formation of $\mathbf{3}$ in $33 \%$ yield after $3 \mathrm{~h}$ reaction time at $-20^{\circ} \mathrm{C}$. We were delighted by the finding that the allylation reaction was accelerated to a great extent when the exceptionally bulky Lewis acid methylaluminum bis(2,6-di-tert-butyl-4-methylphenoxide) (MAD) was used..$^{8,9}$ Ten mol\% of MAD catalyzed the formation of 3 in $87 \%$ yield within $3 \mathrm{~h}$ at $-20{ }^{\circ} \mathrm{C}$ (Table 1, Entry 4). ${ }^{8}$ Introduction of electron-withdrawing groups in the para- position of the bulky phenol ligands resulted in further acceleration of the rate. Thus, methylaluminum bis(4-bromo-2,6-di-tert-butyl-phenoxide) (MABR $)^{8,9}$ performed the reaction between $\mathbf{1}$ and $\mathbf{2}$ to yield the desired product 3 in excellent yield (93\%) within $1 \mathrm{~h}$ at $-20^{\circ} \mathrm{C}$ (Table 1 , Entry 5). It turned out that MABR is the reagent of choice for the catalytic allylation of aldehydes with allyltributylstannane. It is noteworthy that aluminum tris(2,6-diphenylphenoxide) (ATPH) ${ }^{8,9}$ which is known to complex carbonyl functionalities very tightly due to its bowl-like shape ${ }^{11}$ is capable of promoting catalytic allylation of benzaldehyde as well (Table 1, Entry 6). Bulkiness of the phenoxide ligands in the organoaluminum Lewis acids seems to be a prerequisite for catalytic activity and efficiency. This might be due to decreased unfavorable interactions of the bulky aluminum reagent with the reaction products $\left(\mathrm{ROSnBu}_{3}\right)$ which would result in reduced catalytic efficiency.

Table 1. Allylation of Benzaldehyde 1 Catalyzed by Various Lewis Acids

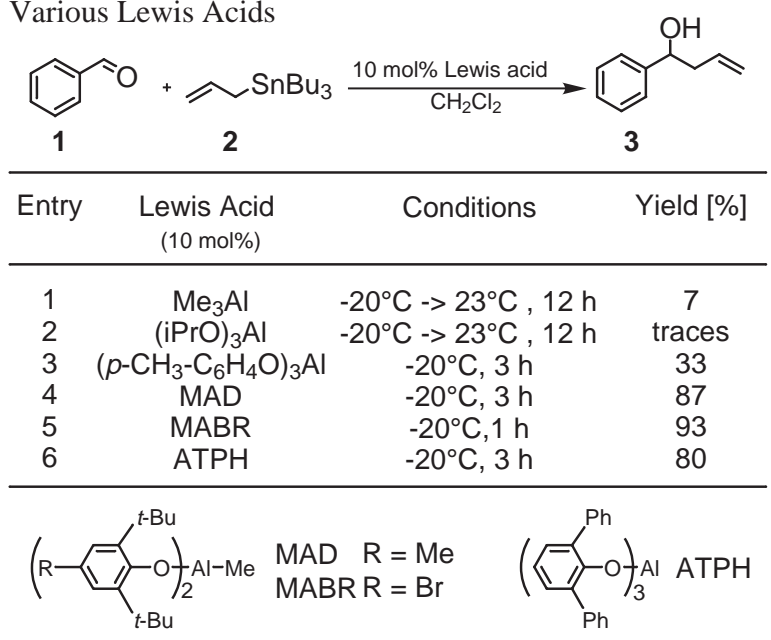

We further investigated the scope of the MABR catalyzed reaction of various aldehydes with allyltributylstannane. Table 2 summarizes the results obtained. Characteristic features are: (1) aromatic aldehydes were allylated in excellent yields within short reaction times (Entries 1-4). (2) In the reaction with a linear aliphatic aldehyde prolonged reaction time was necessary and the yield was lower (Entry 5). Lower reaction temperature $\left(-78^{\circ} \mathrm{C}\right)$ effected the suppression of side reactions and best yields. (3) When a $\alpha$-substituted aliphatic aldehyde was employed the cor- 
responding homoallylic alcohol was formed in high chemical yield but low stereoselectivity (Entry 6). (4) In the reaction with $\alpha, \beta$-unsaturated aldehydes the 1,2-addition proceeded exclusively (Entry 7).

Table 2. Allylation of Various Aldehydes Catalyzed by $10 \mathrm{~mol} \%$ MABR

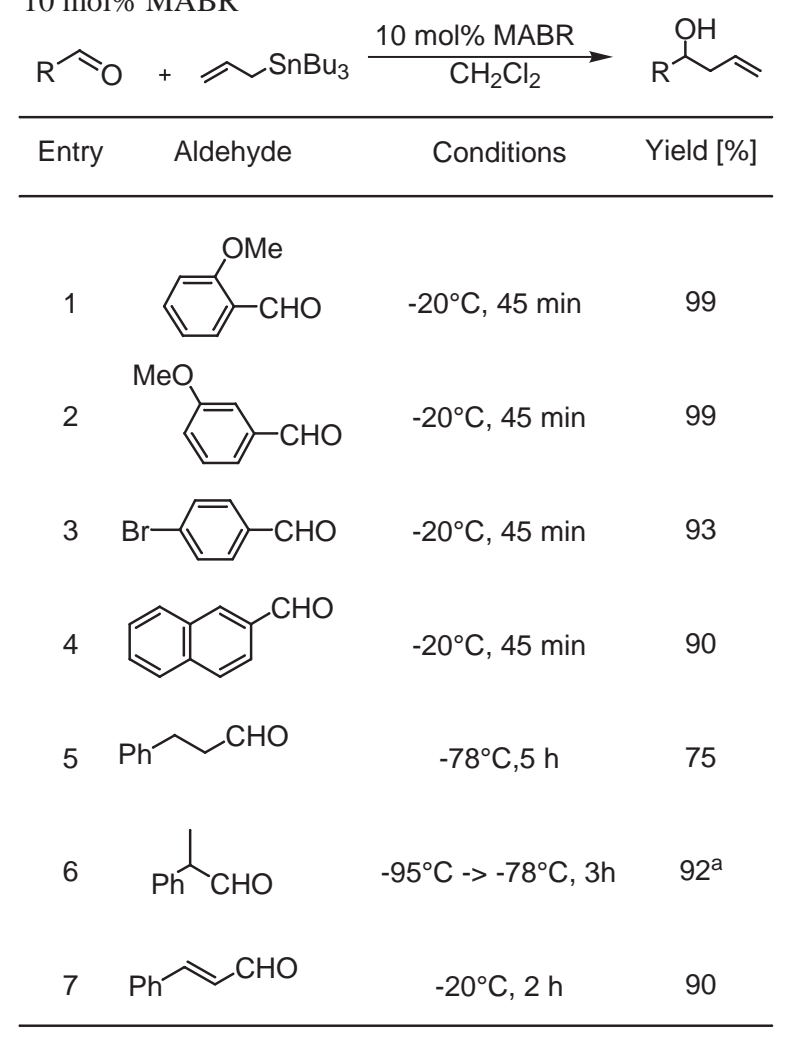

a As 1:1 mixture of diastereomers.

ATPH has been known to tightly complex carbonyl functionalities in the cavity of its bowl-shape ligand scaffold. ${ }^{11}$ It has been reported that ATPH is able to discriminate between structurally similar aldehydes and thereby facilitates the selective functionalization of a less hindered aldehyde as it has been demonstrated for hetero-Diels-Alder and aldol reactions. ${ }^{12}$ Recently it has been shown that Diels-Alder reactions between a carbonyl and diene due to encapsulation of both substrates by ATPH can be achieved. ${ }^{13}$ In all the reported examples stoichiometric amounts or even an excess of ATPH (up to 2.2 eq.) has to be employed to achieve the desired selectivities. Encouraged by our results obtained in the reaction between aldehydes and allyltributylstannane catalyzed by bulky aluminum reagents we investigated whether these reagents are capable to perform chemoselective catalytic allylation of one alcohol out of an equimolar mixture of two structurally different aldehydes (Scheme 1).

In our initial investigation it turned out that treatment of an equimolar mixture of hexanal $\mathbf{4}$ and trimethylacetaldehyde 5 with $5 \mathrm{~mol} \%$ ATPH $(1.00 \mathrm{mmol}$ of each aldehyde were treated with $0.10 \mathrm{mmol}$ of ATPH) at $-78{ }^{\circ} \mathrm{C}$ and subsequent addition of allyltributylstannane resulted in the

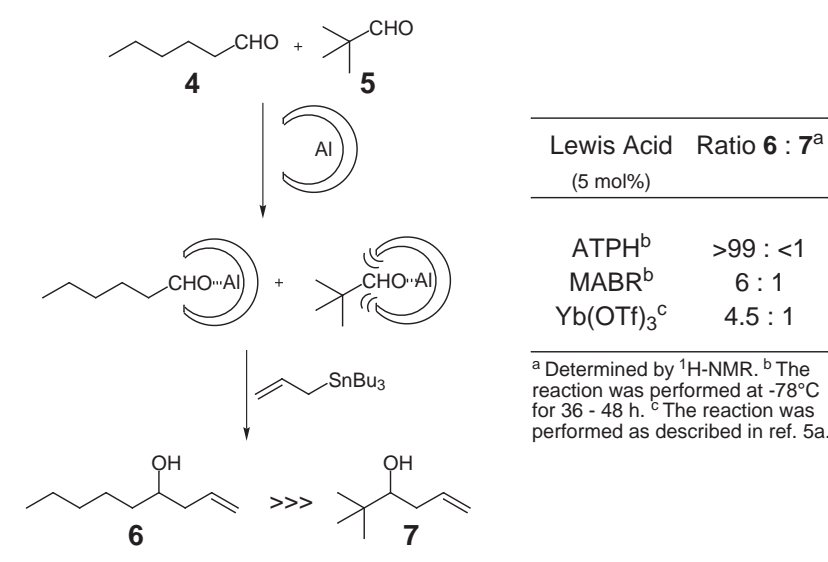

Scheme 1

selective allylation of the less hindered aldehyde to form 6 exclusively (Scheme 1). The formation of the homoallylic aldehyde 7 through allylation of trimethylacetaldehyde 5 was not detected by means of TLC and ${ }^{1} \mathrm{H}$ NMR analysis. In marked contrast $\mathrm{MABR}$ and $\mathrm{Yb}(\mathrm{OTf})_{3}$ afforded the allylation with sufficiently lower chemoselectivity (Scheme 1).

Selected examples for the catalytic allylation of different aldehydes by ATPH are listed in Table 3.

Table 3. Chemoselective Allylation between Two Different Aldehydes with $5 \mathrm{~mol} \%$ ATPH

Homoallylic Alcohol
Yield [\%] (Ratio) $^{\mathrm{a}}$

Table 3 demonstrates that ATPH used in catalytic amounts is able to promote highly selective allylation of two aliphatic aldehyde carbonyl functionalities which differ in their steric constraints. Thus, hexanal $\mathbf{4}$ when it is in an equimolar mixture with trimethylacetaldehyde or cyclohexanecarboxaldehyde, respectively, is recognized by the Lewis acid receptor ATPH and selectively allylated in good yield (Entries 1, 2). Unfortunately, attempted selec- 
tive functionalization of one aldehyde out of a mixture of hexanal and benzaldehyde led to disappointing results (Entry 3). However, when two aldehydes of similar steric demands were employed (benzaldehyde and cyclohexanecarboxaldehyde) functionalization of the aromatic aldehyde proceeded with satisfying selectivity (Entry 4). Furthermore, chemoselective allylation of two sterically different aromatic aldehydes can be achieved. Thus, treatment of an equimolar mixture of benzaldehyde and mesitaldehyde with 5 mol\% ATPH and allyltributylstannane effected the allylation of benzaldehyde predominantly (Entry 5).

In conclusion, we have introduced bulky aluminum Lewis acids as new efficient catalysts for the allylation of a variety of aldehydes with allyltributylstannane. In addition, it has been demonstrated that catalytic amounts of the carbonyl receptor ATPH are sufficient for the recognition of a less hindered or aromatic aldehyde and its chemoselective allylation. Strategies which further enhance the catalytic activity of the bulky monomeric aluminum reagents, as well as an enantioselective process are currently under investigation.

\section{Acknowledgment}

This work has been supported by the Ministry of Education, Science and Culture of the Japanese Government. A.M. thanks the European Union and Japan Society for the Promotion of Science for the award of a postdoctoral scholarship.

\section{References and Notes}

(1) Reviews: (a) Roush W. R. In Comprehensive Organic Synthesis; Trost, B. M.; Fleming I.; Heathcock, C. H., Eds.; Pergamon Press: Oxford U.K., 1991, Vol. 2, p 1.

(b) Yamamoto, Y.; Asao, N. Chem. Rev. 1993, 93, 2207.

(2) Ishihara, K.; Mouri, M.; Gao, Q.; Maruyama, T.; Furuta, K.; Yamamoto, H. J. Am. Chem. Soc. 1993, 115, 11490.

(3) Yanagisawa, A.; Nakashima, H.; Ishiba, A.; Yamamoto, H. J. Am. Chem. Soc. 1996, 118, 4723.
(4) (a) Costa, A. L.; Piazza, M. G.; Tagliavini, E.; Trombini, C. Umani-Ronchi, A. J. Am. Chem. Soc. 1993, 115, 7001.

(b) Keck, G. E.; Tarbet, K. H.; Geraci, L. S. J. Am. Chem. Soc. 1993, 115, 8467. (c) Gauthier, D. R.; Carreira, E. M. Angew. Chem. Int. Ed. Engl. 1996, 35, 2363.

(5) (a) Bedeschi, P.; Casolari, S.; Costa, A. L.; Tagliavini, E.; Umani-Ronchi, A. Tetrahedron Lett. 1995, 36, 7897.

(b) Casolari, S.; Cozzi, P. G.; Orioli, P.; Tagliavini, E.; UmaniRonchi, A. Chem. Commun. 1997, 2123.

(6) Motoyama, Y.; Narusawa, H.; Nishiyama, H. Chem. Commun. 1999, 131.

(7) (a) Aspinall, H. C.; Browning, A. F.; Greeves, N.; Ravenscroft, P. Tetrahedron Lett. 1994, 35, 4639. (b) Aspinall, H. C.; Greeves, N.; McIver, E. G. Tetrahedron Lett. 1998, 39, 9283.

(8) Review: Saito, S.; Yamamoto, H. Chem. Commun. 1997, 1585.

(9) Bulky aluminum Lewis acids (MAD, MABR, ATPH) are readily prepared by treatment of $\mathrm{Me}_{3} \mathrm{Al}$ with the corresponding amounts of phenol in $\mathrm{CH}_{2} \mathrm{Cl}_{2}$ at room temperature for $0.5-1 \mathrm{~h}$ with rigorous exclusion of air and moisture. These reagents can be used without further purification for all the reactions described here.

(10) The experimental procedure for the reaction of benzaldehyde with allyltributylstannane is representative. To a solution of MAD (0.10 mmol) in $\mathrm{CH}_{2} \mathrm{Cl}_{2}(4 \mathrm{ml})$ benzaldehyde (100 $\mu \mathrm{l}$, $1.00 \mathrm{mmol}$ ) was added at $-20^{\circ} \mathrm{C}$. After subsequent addition of allyltributylstannane (320 $\mu \mathrm{l}, 1.03 \mathrm{mmol})$ stirring was continued for $3 \mathrm{~h}$ at $-20^{\circ} \mathrm{C}$. Thereafter, the reaction mixture was poured on a conc. $\mathrm{NaHCO}_{3}$ solution and extracted three times with $\mathrm{CH}_{2} \mathrm{Cl}_{2}$. The combined extracts were dried over $\mathrm{MgSO}_{4}$, and concentrated. Silica gel column chromatography (ethyl acetate/hexane $=1 / 10$ ) yielded the homoallylic alcohol 3 (129 mg, 87\%) as a colorless oil.

(11) Maruoka, K.; Imoto, H.; Saito, S.; Yamamoto, H. J. Am. Chem. Soc. 1994, 116, 4131.

(12) Maruoka, K.; Saito, S.; Yamamoto, H. Synlett 1994, 439.

(13) Ooi, T.; Kondo, Y.; Maruoka, K. Angew. Chem. Int. Ed. Engl. 1998, 37, 3039. 